\title{
Awareness, attitudes and participation of teaching staff towards the open content movement in one university
}

Peter Reed*

Learning Innovation, Learning and Research Technologies, Manchester Metropolitan University, Manchester, UK

(Received 11 April 2012; final version received 16 July 2012)

This research investigates the current awareness of, and participation in, the open content movement at one UK institution for higher education. The open content movement and the open educational resources can be seen as potential methods for reducing time and cost of technology-enhanced learning developments; however, its sustainability and, to some degree, its success are dependent on critical mass and large-scale participation. Teaching staff were invited to respond to a questionnaire. Respondents $(n=59)$ were open to the idea of sharing their own content and, similar to other studies, demonstrated existing practices of sharing resources locally amongst colleagues; however, there was little formal, large-scale sharing using suitable licenses. The data gathered concurs with other research suggesting a lack of awareness to the Creative Commons licenses as well as a lack of participation in large open educational resource repositories.

Keywords: open educational resources; staff attitudes; sustainability

\section{Introduction}

Based on the assertion that the sustainability and, to some degree, the success of the open content movement is reliant on wide participation and a critical mass of “open" content (Downes 2007; Friesen 2009; Wiley and Gurrell 2009), the purpose of this study was to gain an understanding of the current awareness of, and attitudes towards, participation in the open content movement amongst teaching staff at a university. In doing so, this work will build upon the growing published research in this area. This paper reflects upon the awareness and engagement to "The Movement" in relation to available literature and concludes with recommendations or areas for focus pertinent to the university and other higher education institutions (HEIs) committed, or indeed looking to commit, to the open content movement.

Sharing of educational resources is not a new phenomenon (Attwell and Pumilia 2007). Indeed, teaching staff have been sharing PowerPoint presentations and overhead projector transparencies for many years - such materials are now considered open courseware (OCW), open content, open educational resources (OERs), or even reusable learning objects (RLOs). In fact, the terminology with which "open" teaching and learning materials are referred to is increasingly used interchangeably despite subtle differences (Attwell and Pumilia 2007; Lane 2009;

*Corresponding author. Email: P.Reed@mmu.ac.uk 
McGill et al. 2008). However, they are typically common in their intent for being shared openly amongst learners and teachers alike, with permission to remix materials in other contexts.

\section{Defining "open"}

A commonly used definition of OER is:

Open Educational Resources are digitised materials offered freely and openly for educators, students and self-learners to use and re-use for teaching, learning and research. (Hylén, 2006, p. 49)

Put quite simply, "The two most important aspects of openness have to do with free availability over the Internet and as few restrictions as possible on the use of the resource" (Hylén 2006, p. 49), thereby opening the potential to benefit society as a whole (McGill et al. 2008). This includes the removal of barriers (technical, price and legal) to allow "the end-user to not only use or read the resource but also to adapt it, build upon it and thereby reuse it, given that the original creator is attributed for her work" (Hylén 2006, p. 49). Schaffert and Geser (2008) relate the concept of "openness" in OER to four key aspects; open access, open licensing, open format and open software, and for something to be truly open, it should reflect all four (Schaffert and Geser 2008). To this end, Hilton et al. (2010) suggest, "openness is not like a light switch that is either 'on' or 'off'. Rather, it is like a dimmer switch, with varying degrees of openness" (Hilton et al. 2010, p. 38).

With this in mind, the Creative Commons (CC) licenses have played an integral role in the development of the movement. The ease of publishing, sharing and reusing existing content is increased through the application of the free licenses, which were intentionally developed to encourage such ideas (Atkins, Brown and Hammond 2007). Sites such as YouTube, Vimeo, Flickr and Wikipedia have adopted $\mathrm{CC}$ into their work streams, massively impacting upon the number of $\mathrm{CC}$ resources available. Having said that, numerous authors identify licensing as one of the key challenges in the participation in the open content movement and highlight confusion amongst academic staff around their implementation (Attwell and Pumilia 2007; Hylén 2006; Lane 2009).

Participation in the open content movement - "a response to the rising costs of education, the desire for access to learning in areas where such access is difficult, and an expression of student choice about when and how to learn" (Johnson et al. 2010, p. 6) - can be a possible solution to the expensive "reinventing of the wheel" that inevitably occurs within institutions across the higher education sector (Littlejohn and Pegler 2007; Seonghee and Boryung 2008). Perhaps, taking the lead from other nations (particularly the United States), the UK drive for sustainable approaches to digital content development, through the development, sharing and reuse of OER, is led by the Higher Education Funding Council for England (HEFCE), in concurrence with the Higher Education Academy (HEA) and Joint Information Systems Committee (JISC).

\section{Barriers to the "movement"}

Various barriers to participation in the open content movement have been documented, ranging from institutional, personal, technical and disciplinary. 
The 2010 Horizon Report highlights some of the common challenges of sharing, repurposing and reusing scholarly works, including concerns about intellectual property, copyright and student-to-student collaboration. It also acknowledges the widespread belief that reward structures, reputation systems and peer review are key challenges that institutions need to solve (Attwell and Pumilia 2007; Charlesworth et al. 2007; Hylén 2006; Seonghee and Boryung 2008).

With little or no institutional or peer recognition or encouragement, there is little incentive for faculty members to take on the extra burden of developing and refining OER content. (Yuan, Macneill and Kraan, 2008, p. 15)

In reviewing JISC projects, the "Sharing eLearning Content" (SELC) report suggests that sharing in the UK occurs on two levels - small-scale sharing between colleagues on CDs, pen drives, and so on, and through funded projects "whose aim is to stimulate this activity. Often, this activity ceases or diminishes once the funding finishes" (Charlesworth et al. 2007, p. 13). The report suggests the higher education sector demonstrates little formal, large-scale sharing through repositories, with suitable licensing applied. Rather, higher education demonstrates much more smallscale, informal sharing amongst colleagues and collaborators. Despite this, the authors suggest such low scale participation will not ease concerns around sustainability as large-scale formal mechanisms are needed to improve the quality and cost-effectiveness of teaching.

The lack of a central channel for sharing within an institution is often cited as the primary factor for the lack of collection and sharing of digital resources (Friesen 2009; Seonghee and Boryung 2008); "Throughout the years, the same materials have been recreated frequently. This repetition comes at the expense of time, money, and labor from both the faculty and parent organization's perspectives" (Seonghee and Boryung 2008, p. 284). The authors go on to highlight that participants did not share/ exchange materials because they did not know who needed them nor were they aware of the means by which such sharing could take place (Seonghee and Boryung 2008).

The SELC Report also highlighted key concerns around ownership of works and IPR. "Who owns materials" is a common debate - some believe such ownership rests with the individual academics, some think with the institution and some think with both:

Many institutions either don't have a clear policy on who owns the rights in materials produced by staff and students, haven't publicised it if they have, or don't adhere to it.

(Charlesworth et al. 2007, p. 12)

Finally, the author's personal experiences in supporting the use of learning technologies and OER in UK higher education institutions have identified particular instances where content is deemed too valuable to give away, especially when they have the potential to generate income. This is likely to be specific to the individuals (and often by academic managers) involved in these cases. However, this is a viewpoint that could possibly be shared by others and could prove to be a major challenge to the open content movement in an era of economic uncertainty.

\section{Sustainability}

While participation in the open content movement might provide a solution to the concerns of sustainability in relation to technology-enhanced learning, the 
movement has challenges of being sustainable in itself (Atkins, Brown, and Hammond, 2007; Yuan, MacNeill, and Kraan, 2008), that is "How do we keep funding activities whose main purpose is to be free of charge once foundation funding goes away?" (Wiley 2005). Downes (2007) also questions the sustainability of the movement, in that, "If resource users do not pay for their production and distribution, for example, then how can their production and distribution [be] maintained?'. Friesen highlights the lifespan of many inactive or discontinued projects correlating "broadly to the timescales typical for funding research and development projects", which on average showed to be less than 3 years (Friesen, 2009). To this end, project funding around OER is increasingly pursuing this notion of sustainability beyond the funding period - see for example, the HEFCE/HEA/ JISC 14/08 OER call http://www.jisc.ac.uk/fundingopportunities/funding_calls/2008/ 12/grant1408.aspx (HEFCE/HEA/JISC, 2008).

Downes expands this discussion by synthesising various models that impact upon the sustainability of OER, and suggests, "The sustainability of an OER network is based not simply on financing but on a number of inter-related factors, including funding, technical considerations, content models and even staffing" (Downes, 2007, p. 40). Wiley (2005) suggests decentralised systems are more scalable and thus sustainable: "Wikipedia has two employees and well over a million articles in multiple languages. We need to learn this lesson if open education is really going to reach out and bless the lives of people" (Wiley, 2005).

Friesen (2009) picks up this sustainability debate and suggests common characteristics amongst those initiatives/projects that have become inactive or discontinued in the last 10 years. The characteristics include:

First, even though most projects began after MIT's initiative in open courseware, none prioritized the collection of contents that were in the public domain or that were subject to Creative Commons licensing.

Second, their collection mandates were not limited to a specific subject area or to a particular community of subject specialists; instead, all of the projects shown included all educational subjects and topics.

Third, half of the projects shown began between 2001 and 2003. (Friesen, 2009, p. 7)

Although the Friesen (2009) and Seonghee and Boryung (2008) studies took place in Canada and South Korea, respectively, there is no reason to suggest their findings, such as interventions for local sharing, are not equally important to UK Institutions involved in engaging with open education locally, nationally and internationally.

\section{Methods}

This case study hoped to gain insight into the current awareness of attitudes towards, and participation in, the open content movement. More specifically, Jenson and Rodgers may view this within their typology as a "snapshot" case study, as it is a detailed, objective study of one research entity at one point in time (Jensen and Rodgers 2001). As such, the data, findings and conclusions are representative of the point in time at which the research was conducted and may be subjected to change as a result of further initiatives and research.

An additional consideration with such research is that due to the "snapshot" nature, it is difficult to generalise, as the underlying sample size is in effect, one higher 
education institution. Having said this, Flyvbjerg (2006) challenges the notion that case study research cannot be generalised - "it depends on the case one is speaking of and how it is chosen ... the strategic choice of case may greatly add to the generalizability of a case study" (Flyvbjerg 2006, p. 226), and Blaxter, Hughes and Tight (2006) suggest generalisations can be made from a "specific instance to a more general issue" (Blaxter, Hughes and Tight, 2006, p. 74).

With this in mind, comparisons will be made of other studies whenever possible.

\section{Questionnaires}

In late 2010, a questionnaire was developed using the institution's subscription to Bristol Online Surveys (BOS) and distributed via email to 190 staff involved in at least some elements of teaching activity at Edge Hill University, Lancashire, UK, including academic staff from the university's three faculties: Faculty of Health $(\mathrm{FoH})$, Faculty of Education (FoE) and the Faculty of Arts and Science (FAS). The questionnaire was also sent to teaching staff from central non-academic departments, that is, Teaching and Learning Development Unit (TLDU), Fellows of the Centre for Excellence in Teaching and Learning, and Teaching and Learning Fellows.

The questionnaire contained a mixture of open and closed questions to gauge awareness to various aspects of the open content movement, as well as current and future practice related to sharing and reusing content. For example,

'Are you aware of Jorum?' is a simple question that will gather basic information relating to the awareness of Jorum - a funded project for the development of a national repository for digital content.

The questionnaire has been included in Appendix 1.

Few other studies have researched the attitudes towards reuse; however, one very similar study, which aimed "to explore staff awareness and behaviours surrounding OER with a focus on attitudes to sharing resources" at De Montfort University has recently been published (Rolfe 2012). Because of the similarity, Rolfe's findings will be presented alongside the results of this research.

\section{Statistical analysis}

A correlation coefficient analysis was conducted on data to determine any connections between experience of reusing content and attitudes towards future sharing and reuse.

\section{Results}

\section{Staff demographics}

Out of the 190 staff contacted, there were 59 responses, representing a response rate of $31 \%$ (Table 1). This is a higher response rate than received for Rolfe's study $(n=50$ out of $307,16 \%)$.

There was a slightly higher response rate from the Faculty of Health staff ( $n=24$, $40 \%$ ) - likely as a result of the prior connections between the staff and the researcher. Staff from central support departments contributed fewer than other areas $(n=5$, $8.5 \%$ ), but the questionnaire was e-mailed to fewer support staff with teaching responsibilities, compared with other faculties. Faculty of Education $(n=11,18.6 \%)$ 
Table 1. Staff demographics.

\begin{tabular}{lllllr}
\hline & FAS & FoE & FoH & Other & Total \\
\hline $\begin{array}{l}\text { Number of responses } \\
\text { Percentage }\end{array}$ & 19 & 11 & 24 & 5 & 59 \\
\hline
\end{tabular}

Notes: FAS $=$ Faculty of Arts and Science; FOE = Faculty of Education; FOH = Faculty of Health.

and Faculty of Arts and Science $(n=19,32.2 \%)$ had fewer prior connections with the researcher.

\section{Awareness of the open content movement}

Respondents were asked if they were aware of specific terms/services related to open education (Table 2). Thirty-two per cent $(n=19)$ of respondents were aware of the "Open Content Movement", 24\% $(n=14)$ of respondents were aware of the CC and $32 \%(n=19)$ of respondents aware of Jorum. Awareness to each was relatively evenly spread across each faculty/area.

Rolfe's research also identified awareness to certain tools/services. Twenty per cent of respondents were aware of Jorum (compared with 32\% in this study). Furthermore, 19\% were aware of the term "Open Educational Resources", which could be compared against the 32\% who were aware of the "Open Content Movement" in this study. The term "Open Content Movement" has not appeared much in previous literature, so rewording in line with Rolfe's study (as OER is more common) may have resulted in even higher awareness.

\section{Experience I attitudes to reusing existing content}

Respondents were asked if they had experience of reusing materials in both their face-to-face and online teaching (Table 3). In both cases, staff were asked if they sought permission or already had rights clearance for reusing materials. Staff were also asked if they would be willing to reuse digital content in the future.

The results indicated that the majority of teaching staff had already reused existing content in their teaching $(88 \%$ of all respondents had reused content in their face-to-face teaching and $68 \%$ of all respondents had reused existing materials online); however, they all had not necessarily sought or already had rights clearance for their use. Less than half of those staff who had reused online content had asked for, or already had, permission to reuse content.

Interestingly, only one respondent was not willing to reuse digital content in the future.

Table 2. Awareness to elements of the open content movement.

\begin{tabular}{lccccc}
\hline & FAS & FoE & FoH & Other & Total \\
$(n=19)$ & $(n=11)$ & $(n=24)$ & $(n=5)$ & $(n=59)$ \\
Awareness to & 5 & 6 & 5 & 3 & $19(32 \%)$ \\
"Open Content Movement" & 4 & 5 & 3 & 2 & $14(24 \%)$ \\
Creative Commons & 6 & 7 & 2 & 1 & $19(32 \%)$ \\
Jorum & & 7 &
\end{tabular}

Notes: FAS $=$ Faculty of Arts and Science; FOE $=$ Faculty of Education; $F O H=$ Faculty of Health. 
Table 3. Attitudes to reusing existing content.

\begin{tabular}{lccccc}
\hline & $\begin{array}{c}\text { FAS } \\
(n=19)\end{array}$ & $\begin{array}{c}\text { FoE } \\
(n=11)\end{array}$ & $\begin{array}{c}\text { FoH } \\
(n=24)\end{array}$ & $\begin{array}{c}\text { Other } \\
(n=5)\end{array}$ & $\begin{array}{c}\text { Total } \\
(n=59)\end{array}$ \\
\hline Reused face-to-face materials & 16 & 10 & 22 & 4 & $52(88 \%)$ \\
Asked for, or already have clearance & 14 & 7 & 22 & 2 & $45(86 \%)$ \\
Reused online materials & 12 & 10 & 14 & 4 & $40(68 \%)$ \\
Asked for, or already have clearance & 4 & 4 & 8 & 3 & $19(47.5 \%)$ \\
Willing to reuse digital content & 18 & 11 & 24 & 5 & $58(98 \%)$ \\
\hline
\end{tabular}

Notes: FAS $=$ Faculty of Arts and Science; FOE $=$ Faculty of Education; FOH =Faculty of Health.

Rolfe's research identified that around $75 \%$ of respondents had already reused and shared content, "mostly with close working colleagues" (Rolfe 2012, p. 4).

\section{Attitudes to sharing content with others}

Respondents were asked to select one option in response to the question, "to what degree would you be willing to share your content?". All respondents said they would be willing to share their own content at some level, with $57 \%(n=34)$ happy to share more openly beyond the university (Table 4). This can be broken down into two categories: use for any not-for-profit users $(n=25,42 \%)$ or open for anybody to reuse $(n=9,15 \%)$.

Rolfe identified that $12 \%$ of respondents were happy to make their content "Openly available to anyone who wants them globally". This relates to a similar figure of $15 \%$ of respondents in this study willing to share content with "Anybody".

Although the questions asked in this study identified willingness to share more openly, respondents in Rolfe's study demonstrate an opposite attitude, suggesting a stronger willingness to share with close-working colleagues $(66 \%)$. Perhaps the specifics of the question might explain this contradiction; the question in this study focused on willingness in the future, whereas Rolfe's focused on current practice (which of course might be different to their willingness).

Interestingly, in considering the reuse of their own materials, one free-text response was, "It is very difficult to stop people using our material". Another response was, "It's being attributed correctly that is important. I have previous experience of whole groups of people using my materials etc and taking my name off and adding theirs. Which was annoying."

Table 4. Attitudes to sharing content with others.

\begin{tabular}{lccccc}
\hline & $\begin{array}{c}\text { FAS } \\
(n=19)\end{array}$ & $\begin{array}{c}\text { FoE } \\
(n=11)\end{array}$ & $\begin{array}{c}\text { FoH } \\
(n=24)\end{array}$ & $\begin{array}{c}\text { Other } \\
(n=5)\end{array}$ & $\begin{array}{c}\text { Total } \\
(n=59)\end{array}$ \\
\hline Not at all & 0 & 0 & 0 & 0 & 0 \\
Friends only & 1 & 0 & 0 & 0 & $1(<2 \%)$ \\
Department/faculty & 4 & 1 & 5 & 0 & $10(17 \%)$ \\
Institution & 2 & 4 & 6 & 2 & $14(24 \%)$ \\
Anybody not-for-profit & 9 & 4 & 12 & 0 & $25(42 \%)$ \\
Anybody & 3 & 2 & 1 & 3 & $9(15 \%)$ \\
\hline
\end{tabular}

Notes: FAS $=$ Faculty of Arts and Science; FOE $=$ Faculty of Education; FOH $=$ Faculty of Health. 
Table 5. Awareness to ownership of works.

\begin{tabular}{lccccc}
\hline & $\begin{array}{c}\text { FAS } \\
(n=19)\end{array}$ & $\begin{array}{c}\text { FoE } \\
(n=11)\end{array}$ & $\begin{array}{c}\text { FoH } \\
(n=24)\end{array}$ & $\begin{array}{c}\text { Other } \\
(n=5)\end{array}$ & $\begin{array}{c}\text { Total } \\
(n=59)\end{array}$ \\
\hline You individually & 5 & 2 & 2 & 1 & $10(17 \%)$ \\
Department/Faculty & 1 & 1 & 1 & 0 & $3(5 \%)$ \\
Institution & 4 & 3 & 8 & 2 & $17(29 \%)$ \\
Both you \& Institution & 8 & 4 & 11 & 2 & $25(42 \%)$ \\
Other & 1 & 1 & 2 & 0 & $4(7 \%)$ \\
\hline
\end{tabular}

Notes: FAS $=$ Faculty of Arts and Science; FOE $=$ Faculty of Education; FOH $=$ Faculty of Health.

\section{Awareness to ownership of works}

The questionnaire identified confusion amongst academic staff regarding ownership and the work they create (Table 5). Shared ownership between the creator and the institution was the most common response $(n=25,42 \%)$, followed by the institution $(n=17,29 \%)$. Free-text comments suggested a further lack of clarity in this area.

This confusion aligns with Rolfe's (2012) research, which suggested roughly half of respondents thought copyright resided with the university, 24\% were unclear and $16 \%$ believing it resided with the individual.

\section{Connections between responses}

In this study, correlation coefficient analysis was conducted on data to determine if relationships existed between certain responses (Table 6). Data demonstrate significant correlation between respondents' willingness to reuse digital content and their 'experience of reusing content in face-to-face teaching', 'experience of reusing digital content', and 'willingness to share content for not-for-profit users'.

\section{Discussion}

It is felt that the response rate $(n=59)$ is reasonable for a voluntary questionnaire and demonstrates awareness of various aspects of the open content movement at this point in time (questionnaire sent late 2010).

The data suggest that teaching staff are already reusing existing content, and willing to share content in the future, despite the lack of any formal policies to encourage this practice. This could support Hylen's viewpoint that "OER is still mostly a bottom-up phenomenon, where the managerial level of the institutions are not involved and not aware of the activities going on" (Hylén 2006, p. 52). It also reinforces Rolfe's research suggesting small-scale local sharing is more common than more formal approaches to sharing (Rolfe 2012). It might also contradict conclusions of Seonghee and Boryung (2008) that faculty tends to focus on individual academic

Table 6. Correlation coefficient analysis comparing responses.

\begin{tabular}{ll}
\hline & Willingness to reuse digital content \\
\hline Experience of reusing content in face-to-face teaching & 0.9995 \\
Experience of reusing digital content & 0.952 \\
Willingness to share content for not-for-profit users & 0.995 \\
\hline
\end{tabular}


goals and visions rather than working towards common goals. The authors believe academics' desire to share knowledge is relatively weak, yet the data collected in this survey, and that of Rolfe's, suggest teaching staff are positive towards sharing/ common goals. However, some free-text comments do suggest anxiety towards the proper attribution of academic work/materials and, in some cases, citing negative experiences.

Despite this, one striking challenge emerges - although staff are willing to share and, in many cases in this study, willing to share openly, they are not doing so to any formal large-scale degree, that is, through specific OER repositories and open licenses. For appropriate use and reuse of content, more attention must be drawn to copyright and licensing (Hylén 2006). This is demonstrated by the lack of awareness and application of the CC licenses alongside the use of Jorum (Questions 6 and 7). This could support the common belief (Attwell and Pumilia 2007; Charlesworth et al. 2007; Friesen 2009; Yuan et al. 2008) that "raising the awareness of copyright and licenses is an important challenge for both the OER and OA movements" (Hylén 2006). This does also corroborate Seonghee and Boryung's (2008) conclusion that "they [Faculty staff] hesitate to share such materials due to the lack of systems to protect their intellectual assets". This again reinforces the need to raise awareness of the $\mathrm{CC}$ licenses.

On the notion of licensing, question 5 reveals a distinct confusion in relation to the ownership of content developed by academic staff - confusion shared across the literature and in similar studies (Rolfe 2012).

Finally, while sharing is only carried out informally, there is no opportunity for motivated staff and/or students to search and engage with such materials on a more formal basis, which has proven desirable in other studies (Atkins et al. 2007; Conole 2010; Hylén 2006). A logical progression from the informal sharing witnessed here might be the introduction of an institutional repository to help foster a culture of formal sharing. This would put to action the conclusions drawn by some, that a central, local repository will develop further engagement with OER across the institution (Seonghee and Boryung 2008; Friesen 2009). However, this does not only require buy-in from senior management but also the finances to purchase, develop, support and integrate such a system. Furthermore, such integration could lead to, and indeed encourage, wider sharing through services such as Jorum, to benefit the OER movement as a whole.

These findings raise an interesting topic for debate: what constitutes "participation" in the open content movement? Some commentators suggest the OER movement is now starting to reach a critical mass, with institutions worldwide engaged in the creation of OER (Conole 2010; Friesen 2009) however, the informal sharing identified in this, and Rolfe's (2012) study, cannot be classified as being truly "open". By Schaffert and Geser's (2008) definition, they are neither openly accessible (in a repository) nor licensed in such a way so as to encourage reuse. Even in consideration of the dimmer switch analogy introduced earlier, these examples might be situated at the lowest (almost off) position (Hilton et al. 2010).

Somehow encouraging a more formal sharing philosophy amongst teaching staff who are already sharing informally is a key challenge in achieving large-scale participation, something which many authors reinforce is a requirement for costeffectiveness and sustainability (Downes 2007; Friesen 2009; Wiley and Gurrell 2009). 


\section{Conclusions}

Participation, albeit on a small and local scale, is better than no participation at all. This can only be a positive sign for the development of the Open Content Movement. Needless to say, significant work is required if the current levels of awareness/ participation is to scale to suitably render the movement practical, sustainable and ultimately successful. What such "levels" might be, and furthermore the impact and cost required to get there, is somewhat unknown. Also, significant support is required in the creation of new and re-purposing of existing OERs; however, such support is required from a management and strategic level opposed to small/local scale "champions". For example, the OpenSpires project at the University of Oxford (http://openspires.oucs.ox.ac.uk/) is dependent on a team of learning technologists carrying out the technical functions to publish academic podcasts. Therefore, the support must come from the provision of methods to develop OERs that utilise existing skill sets or by enhancing skill sets through staff development. Where academic staff are generating content for themselves, dedicated time to do so has proven critical through free-text comments in this study.

As engagement appears to be a bottom-up phenomenon, the movement should be recognised within institutional strategy and become a priority for faculty and nonacademic departments. A "joined up" approach, where the academic managers recognise and reward excellence in all areas of learning and teaching, including OER, along with the allocation of necessary resources, can only be beneficial. Indeed, one free-text response attributed the lack of participation to available time: "It's a time thing".

Institutional clarification is required with regard to ownership of work/content produced by staff while under contract at higher education institutions. This will serve to clarify misunderstandings that exist both within the institution and across the wider sector.

This research builds upon a small but growing collection of literature focusing upon awareness and attitudes towards the open content movement. This research makes it apparent that the breadth and depth of this topic demands further exploration/research to gain a fuller understanding, and further comparisons need to be drawn between participation of teaching staff across the other higher education sectors. Similar studies, perhaps combining the questionnaire in this study with that of Rolfe's study, might also be of interest to the sector.

\section{Recommendations}

In agreement with much of the literature covered earlier, there are a number of key points that need to be addressed if the university is to engage on a larger scale. Such points will likely be pertinent to similar institutions across the sector; (in no order of importance or priority)

(1) A central repository is required to allow storage, search and retrieval of content. This should work in conjunction with the institutional Virtual Learning Environment (VLE) to allow effortless transition between environments. This may also require close liaison between IT Services and Learning/ Library Services to set up and publicise practices and systems. Existing tools include ePrints, Equella and Blackboard's content system. 
(2) As engagement appears to be a bottom-up phenomenon, the movement should be recognised within institutional strategy and become a priority for faculty and non-academic departments. A "joined up" approach, where academic managers recognise and reward excellence in all areas of learning and teaching, including OER.

(3) Institutional clarification is required with regard to ownership of work/ content produced by staff while under contract at higher education institutions. This will serve to clarify misunderstandings that exist across the sector.

(4) Action on point 3 will also help to feed into awareness-raising activities regarding open licenses, namely, the $\mathrm{CC}$ and their application to OER.

(5) Staff development activities around content searching, retrieval, repurposing and re-licensing content is critical and is linked with action on point 4 . Some higher education institutions already include a focus on OER within their Post Graduate Certificate in Teaching and Learning (or equivalent); however, this was not featured in the higher education institution under investigation.

A further challenge for the global higher education sector is that of accreditation. The rise of such informal learning through open repositories and open courseware sites empowers learners in an unimaginable manner; however, we need to find ways of accrediting this learning for the movement to truly be a successful initiative in relation to personalised formal and informal learning.

\section{Acknowledgements}

The author would like to express gratitude to the blind reviewers for their invaluable comments in preparing this article for publication.

\section{References}

Atkins, D. E., Brown, J. S. \& Hammond, A. L. (2007) A Review of the Open Educational Resources (OER) Movement: Achievements, Challenges, and New Opportunities, The William and Flora Hewlett Foundation, Menlo Park, CA.

Attwell, G. \& Pumilia, P. M. (2007) 'The new pedagogy of open content: bringing together production, knowledge, development, and learning', Science, vol. 6, pp. 211-219.

Blaxter, L., Hughes, C. \& Tight, M. (2006) How to Research, 3rd edn, Open University Press, London.

Charlesworth, A., et al. (2007) 'Sharing eLearning Content - a synthesis and commentary. Final report', Synthesis, 31 (August), p. 39. Available at: http://ie-repository.jisc.ac.uk/46/

Conole, G. (2010) 'A framework for technological intervention,' e4innovation, [online] Available at: http://e4innovation.com/?p=364

Downes, S. (2007) Models for sustainable open educational resources. What resources? Learning, 3, pp. 29-44

Flyvbjerg, B. (2006) 'Five misunderstandings about case-study research', Qualitative Inquiry, vol. 12 , no. 2, pp. 219-245. DOI:10.1177/1077800405284363

Friesen, N. (2009) 'Open educational resources: new possibilities for', International Review of Research in Open and Distance Learning, vol. 10, no. 5, pp. 1-13.

Hilton, J. III., et al. (2010) 'The four "R"s of openness and ALMS analysis: frameworks for open educational resources', Open Learning: The Journal of Open and Distance Learning, vol. 25, no. 1, pp. 37-44. DOI:10.1080/02680510903482132.

Hylén, J. (2006) 'Open educational resources: opportunities and challenges', Proceedings of Open Education 2006: Community, culture and content. September 27-29, Utah State University, pp. 49-63. 
Jensen, J. L. \& Rodgers, R. (2001) 'Cumulating the intellectual gold of case study research', Public Administration Review, vol. 61, no. 2, pp. 235-246.

Johnson, L., et al. (2010) The Horizon Report, The New Media Consortium, Austin, TX.

Lane, A. (2009) 'The impact of openness on bridging educational digital divides', International Review of Research in Open and Distance Learning, vol. 10, no. 5.

Littlejohn, A. \& Pegler, C. (2007) Preparing for Blended Learning, Routledge, London.

McGill, L., et al. (2008) 'Good intentions: improving the evidence base in support of sharing learning materials', Project Report, Available at: http://ie-repository.jisc.ac.uk/265/ 1/goodintentionspublic.pdf

Rolfe, V. (2012) 'Open educational resources: staff attitudes and awareness', Research in Learning Technology, vol. 20, no. 1063519, pp. 1-13. DOI:10.3402/rlt.v20i0/14395.

Schaffert, S. \& Geser, G. (2008) 'Open educational resources and practices', eLearning Papers, [online] Available at: http://dialnet.unirioja.es/servlet/articulo?codigo=2596043\&orden= 157677\&info $=$ link

Seonghee, K. \& Boryung, J. (2008) 'An analysis of faculty perceptions: attitudes toward knowledge sharing and collaboration in an academic institution', Library \& Information Science Research, vol. 30, no. 4, pp. 282-290. DOI:10.1016/j.lisr.2008.04.003.

Wiley, D. (2005) 'Thoughts from the Hewlett Open Ed Grantees Meeting', Iterating Toward Openness, Available at: http://opencontent.org/blog/archives/192\#axzz0qAg9fIHn

Wiley, D. \& Gurrell, S. (2009) 'A decade of development', Open Learning: The Journal of Open and Distance Learning, vol. 24, no. 1, pp. 11-21. DOI:10.1080/02680510802627746.

Yuan, L., Macneill, S. \& Kraan, W. (2008) Open educational resources - opportunities and challenges for higher education, Available at: http://muele.mak.ac.ug/file.php/1/ Student_Reading_Resource/oer_briefing_paper.pdf

\section{Appendix 1.}

Questionnaire

1. Which faculty/service are you in?

Faculty of Arts and Science (FAS)

Faculty of Education (FOE)

Faculty of Health (FOH)

Professional Support Staff (LS, ITS, SOLSTICE, etc.)

2. What subject do you teach?

[Free text]

3. What do you understand of the terms content "reuse" and "repurpose"?

[Free text]

4. Are you aware of the Open Content Movement in HE, or any deliberate attempts to encourage content sharing and reuse?

[Free text]

5. Who owns the content you develop/teach, that is, slides, resources, online resources, etc.?

You (individually)

Department/faculty

Institution

Both you and the institution

Other (please specify)

6. Are you aware of Creative Commons (CC) licensing?

Yes

No 
6a. If yes, have you ever reused CC licensed content?

Yes

No

Don't know

6b. Have you ever applied CC licensing to your content/work?

Yes

No

7. Have you ever heard of Jorum (JISC-funded National repository for digital content)?

Yes

No

7a. If yes, have you ever uploaded content to Jorum?

Yes

No

7b. Have you ever searched Jorum for content?

Yes

No

8. Use this free-text box to leave any general comments related to the questions above ... [Free text]

9. In your face-to-face teaching, have you ever reused other people's materials (handouts, slides, etc.)?

Yes

No

Don't know

9a. If yes, did you ask for permission or do you already have clearance (e.g. CC/GNU)?

Have no permission

Ask for permission

Already had clearance

10. Have you ever reused other people's online materials (Websites, online guides, tutorials, etc.)?

Yes

No

10a. If yes, did you ask for permission or did you already have clearance (e.g. CC/GNU)?

Have no permission

Ask for permission

Already had clearance

11. Would you be willing to reuse other people's content in the future (if aligned with your curriculum)?

Yes

No

12. Use this free text box for any comments or expansion on any of your answers above [Free text]

13. Which skills do you think you currently possess ...

Locate existing digital materials 
Evaluate suitability of existing digital materials

Reuse existing digital materials in their complete form

Repurpose specific elements of existing digital resources and embed within your own

14. Provided you were attributed correctly, to what degree would you be willing to share your content?

Not at all

Only with friends

Within my faculty/department

With anybody in my institution

Anybody as long as it is not-for-profit

Anybody

15. What resources would you most likely reuse, or are you open to all types? (select all that apply)

Context-specific resources (simulations, case studies, interviews, interactive elements, etc.)

Generic resources (study skills, research methods, reflections, etc.)

None

Other (Please specify)

16. Any other comments?

[Free text] 